\title{
A rare encounter: Charcot marie tooth disease
}

\author{
Ramnath Santosh Ramanathan* \\ Neurology, Vascular Neurology, Akron Neurology Inc, Akron, Ohio, USA
}

We report a rare case, Charcot Marie Tooth (CMT) disease which has a dearth of published reports, though it is one of the most common heritable neuropathy. CMT is also known as HMSN (hereditary motor and sensory neuropathies) or Peroneal Muscular Atrophy and these diseases can be classified according to the pattern of transmission (autosomal dominant, autosomal recessive, $\mathrm{X}$ linked), electrophysiological findings (axonal, demyelinating) and causative mutant gene. The different classes of this disorder have been divided into the primary demyelinating neuropathies (CMT1, CMT3, and CMT4) and the primary axonal neuropathies (CMT2) [1].

A 37 year old non diabetic, normotensive male came with chief complaints of gradual onset difficulty in walking since 2 years with wasting of both lower limbs. Patient did not take any treatment for the same since the onset of the problem. A year later he developed wasting of both upper limbs especially the small muscles of hands as well as increased difficulty in walking. Patient had severe burning sensation of both the lower limbs and sole since 3 to 4 months which compelled the patient on taking medical advice. Patient had a positive family history in which patient's one of the maternal uncle, other maternal uncle's two daughters and patient's brother had similar illness but none of them had taken any treatment or had a definitive diagnosis. On examination patient was conscious oriented with normal cranial nerves, muscle strength in both lower limbs $4 / 5$ at the hip, knee and ankle, with wasting in both thighs and calf muscles, with inverted champagne bottle appearance and pes cavus, had normal muscle strength in both upper limbs with weak handgrip on both sides and wasting of small muscles of both hands and sensory loss with distal reduction in deep tendon reflexes in both lower limbs. Romberg's test was positive and tandem walking was not possible. Vitamin B12 level was normal. HIV and ANA testing were negative. CSF examination was normal. Electrodiagnostic studies showed generalized demyelination with Nerve conduction velocities (unrecordable velocity in bilateral median and ulnar nerve) showing motor distal latencies that were proportionately prolonged and absent sensory nerve action potentials. There was no electrophysiological evidence of motor conduction blocks or abnormal temporal dispersion. Based on the history, strong positive family history, clinical examination and electrophysiological investigations the diagnosis of Charcot-Marie-Tooth polyneuropathy was made.

Copyright: (C2016 Ramanathan RS. This is an open-access article distributed under the terms of the Creative Commons Attribution License, which permits unrestricted use, distribution, and reproduction in any medium, provided the original author and source are credited.
CMT was discovered in 1886 by three physicians, Jean-MartinCharcot, Pierre Marie, and Howard Henry Tooth. Presently incurable, this disease is one of the most common inherited neurological disorders with a prevalence of 1 person per 2500 population and incidence of CMT type 1 is 15 persons per 100,000 population; incidence of CMT type 2 is 7 persons per 100,000 population. Persons with CMT X represent at least $10-20 \%$ of people with the CMT syndrome [2]. Mutations in structural myelin genes or the transcription factors responsible for their expression lead to demyelination (ie, PMP22, P0, CX32, EGR2). P0, linked to Charcot-Marie-Tooth disease type 1B (CMT1B), is the most abundant protein in compact myelin and is a cell adhesion molecule (CAM). PMP22, linked to CMT1A, is a protein of unclear function that has features of both a channel protein and a CAM. Schwann cells also express Cx32, linked to X-linked Charcot-Marie-Tooth Disease type 1 (CMTX1), which belongs to the connexin family. EGR2 is a transcription factor linked to Charcot-Marie-Tooth disease type 1D (CMT1D). More recently, mutations in the LITAF (lipopolysaccharideinduced tumor necrosis factor-alpha) complex were found to account for CMT1C; these mutations are involved in the proliferation and apoptosis in Schwann cells carrying PMP22 alterations. There is no cure for CMT but the use of ascorbic acid has been proposed, and has shown some benefit in animal models [3]. A clinical trial to determine the effectiveness of high doses of ascorbic acid in treating humans with CMT type 1A has been conducted [4]. The 12 months of treatment with high-dose ascorbic acid was safe and well tolerated but the expected efficacy endpoints were not reached [5].

\section{References}

1. Fauci AS, Kasper DL, Longo DL, Braunwald E, Hauser SL, et al. (2008) Peripheral Neuropathy. In: Fauci AS, et al. (Eds), Harrison's Principles of Internal Medicine, (17thedn), United States of America, McGraw-Hill Companies, Inc, 2: 2651-67.

2. Kedlaya D (2009) Charcot-Marie-Tooth Disease [Internet]. Updated: Sep 9, 2009. Available from: http://emedicine.medscape.com/article/1232386-overview

3. Passage E, Norreel JC, Noack-Fraissignes P, Sanguedolce V, Pizant J, et al. (2004) Ascorbic acid treatment corrects the phenotype of a mouse model of Charcot-MarieTooth disease. Nat Med 10: 396-401. [Crossref]

4. “Clinical Trials - Neuromuscular Trial/Study”. 2007-07-18. Retrieved.

5. Burns J, Ouvrier RA, Yiu EM, Joseph PD, Kornberg AJ, et al. (2009) Ascorbic acid for Charcot-Marie - Tooth disease type 1A in children: a randomised, double-blind, placebo-controlled, safety and efficacy trial. Lancet Neurol 8: 537-544. [Crossref]
Correspondence to: Ramnath Santosh Ramanathan, MD, Neurology, Vascular Neurology, Akron Neurology Inc, Akron, Ohio, USA, E-mail: dr.santosh7@gmail.comm

Received: December 12, 2016; Accepted: December 26, 2016; Published: December 29, 2016 